\title{
The Uncertain Texture of Discourse on the Dangerous Psychopath
}

Received: March 28, 2017; Accepted: April 18, 2017; Published: April 24, 2017

\section{Introduction}

The topic tackled by this work concerns the links between two sense-making practices-the medical-psychiatric one and the legal one-in which the relationships between language, cognition and society are traced by discursive modulation of the "certainty/ uncertainty" axis, which characterises the processes of sensemaking activated in representing reality and in the socially shared aspiration of truth [1]. The binding nature of this system is even more evident when, like in this work, two totally different epistemological worlds and communicative registers meet with particular reference to the "mentally ill" perpetrators and victims of crimes.

\section{The Discursive Construction of Psychopaths" "Social Dangerousness"}

A possible discursive matter floating between the problems of mental health and the judicial-legal level, concerns the connection between concepts like "care", "control" and "possibility to foresee or prevent" human behavior, with particular reference to deviant behaviors characterized or modulated by aggressiveness and violence. This connection is portrayed in the concept of "social dangerousness" [2], which indicates the probability of a subject, already considered guilty and responsible by the judge, of repeating the crime (with all its consequences in terms of adopting custodial and non-custodial security measures and punishments stripping or limiting freedom), in the name of and on behalf of the whole community.

Social dangerousness has two sides: the first is only judicial and concerns subjects not characterised by mental infirmity, but fully sound of mind at the moment the crime was committed, and therefore the assessment of the probability that they commit the crime is the exclusive competence of the magistrate; the second is legal medical and psychiatric, or psychologicalforensic, and concerns subjects affected by mental infirmity and thus of unsound mind at the moment of the fact, in the same way assessing the probability of them repeating the crime is dependent on the opinion of clinical and forensic psychologists, who are asked to express their "know whether".

\section{Scardigno R, Grattagliano I, Papapicco C and Mininni G}

\author{
Department of Educational Sciences, \\ Psychology and Communication, University \\ of Bari Aldo Moro, 70121 Bari, Italy
}

\section{Corresponding author: Mininni G \\ giuseppe.mininni@uniba.it}

Professor in Psychology of Communication, Department of Educational Sciences, Psychology and Communication, University of Bari, Italy.

Tel: ++39805714551

Fax: ++39805714606

Citation: Scardigno R, Grattagliano I, Papapicco C, et al. The Uncertain Texture of Discourse on the Dangerous Psychopath. Acta Psychopathol. 2017, 3:3.

Referring to social dangerousness, it is possible to trace a diachronic development which goes from danger intended as an almost "natural" connotation of an individual, intrinsic and unrelated to the treatment, to the so-called "cure conditioned danger" to the cures, aimed-today-a customized, concrete, specific therapeutic project capable of satisfying an ambitious (and risky) dual objective: curing and preventing recurrence of crimes. This appreciable change of direction compared to the past makes it possible to offer more therapeutic possibilities to mentally ill offenders, but simultaneously transfers new obligations, commitments and even responsibilities to the forensic and clinical psychiatrist and psychologist, even in terms of treatment [3].

In our analysis of the requests underlying the two sense-making processes that liaise to tackle social dangerousness, we will highlight the most consolidated discursive practices and the language registers compatible with the expectations rooted in a specific socio-cultural context. All this is substantiated in the scientific paper, which constitutes an extremely important "genre" in the human communication system, not only because a specific scientific community is built on top of it, but also because it reveals the social-epistemic rhetoric that organises the human understanding in the world. 


\section{Aims, Corpus and Method of an Empirical Study}

A study was run on the above issue with the objective to single out the rhetoric-argumentative strategies that organize the construction of knowledge in forensic psychiatry. Such scientific environment is driven by many impulsesof a theoreticalmethodological order that, on the one hand, favour the construction of traces of certainty and that, in a complementary manner, limit the applicability of the knowledge acquired within the field of the social dangerousness of the mentally ill. In our opinion, the social dangerousness of the psychicallyill comes within an "order of the discourse" which engages forensic psychiatrists/ psychologists on two levels: on the one hand they are obliged to construct "certainties" on a theoretical-methodological level which is co-cultivated by the scientific community, with whom they try to be accredited. On the other, since the discursive "genre" means variable levels of assertiveness of the proposals made and considering the criticality and the great responsibility of the applicative implications presented on a judicial, ethical and social level, the references to the "dangerous mentally ill person" will be dotted with many traces of uncertainty.

In order to check our hypotheses, 30 papers published by the prestigious British Journal of Psychiatry (BJP) in the period from 1975 to 2015 were selected, on subjects concerning forensic psychiatry.

In order to enhance the dynamics of the discourses in their contexts, the texts of the papers were subjected to a path of Critical Discourse Analysis which we will call "Diatextual" [4], where it is worthwhile firstly highlighting the "genre" of the discourse. In this specific case, the paper is a discursive event with an argumentative intent, because it is the privileged channel for introducing new discoveries into the scientific community. Indeed, its main purpose is that of inviting other scholars to take charge of its own message, to accept or defend a specific position, to accept any new knowledge produced. Specifically, the comprehension models that we have considered to respond to the research objectives and to the type of texts, are firstly determining a "social-epistemic rhetoric" [5], a construction that, by incorporating references to both the sociologic tradition of the analysis of the "ideologies" and the semiotic investigation on "sign systems", permits a top-down reading of the texts, capable of catching sense perspectives valid for particular groups of positioning. In particular, since rhetoric can be defined as "description of reality through language" [6], as well as since "through rhetorical interaction, people come to accept some ideas as true and to reject others as false. Thus, rhetoric's epistemic function in society can be seen in some ways to be a result of its benefit of testing ideas" [7], then the social-epistemic rhetoric can be a really fruitful devise to gain forms of knowledge constructed in specific communities.

For a bottom-up analysis, a particularly valid perspective from a stylistic-rhetoric viewpoint concerns the aspects of the discursive modulation offered by the pragmatic construct of "mitigation" as it is achieved through "bushes" and "hedges" [8].

\section{Discourse Analysis: Main Results}

Analysing the texts regarding forensic psychiatry in the fortyyear period examined leads to the emergence of features which highlight the complexity of the argument in two macroenvironments of content and two macro-functions determining the construct of the "social-epistemic rhetoric", balancing "social reassurance" against "awareness of the limits". The scientific papers represent the main channel for communicating results and discoveries in biomedical sciences. In this field, more than any other, some characteristics of these texts make the knowledge proposed by them "applicable" to the daily life of people. For example if some information regarding a pathology, a treatment or an operation is defined as being "certain", it is more likely for the scientific community to transform words into reality. If uncertainty should prevail, the application of those cognitions will be enacted much more "cautiously".

\section{The rhetoric of social reassurance}

The objective of scientific communication is to produce reliable and valid theoretical-methodological frameworks and research contexts, in order to obtain control margins and predictability in the indefinite process of knowledge construction. The opening words in all papers are generally assertive so as to emphasise the social relevance of the theme, guaranteed by the presence of references to public and social life, to services and to legislation as well as to the mass media. This trend complies with the "mission" assigned to the introduction in a scientific paper, which is generally mainly aimed at establishing the authors' "research territory" and creating a "niche" to occupy for their contributionfor their contribution to occupy [9].

In general, the strength in the construction of the "rhetoric of reassurance" is specifically represented by the methodological approach: the "methodolatry" seeks a high degree of precision, sometimes even exasperated by the reference to percentage data and statistical analysis. Apart from offering data, a further argumentative method concerns the precise illustration of the procedures, as well as the exposition of the reasons for the choices. These further strategies aim at involving the reader by taking them "behind the scenes" of the research, to further enhance the construction of a trust agreement with the scientific community.

In addition, the function of reassurance seems to be carried out by some strategies of approach and organisation of the discourse. In particular continual reference is made to markers of textual metadiscourse [10], both in the form of logic connectors and gloss practices ('however', 'also', 'in addition', 'therefore'), and by means of frame and endophoric markers ('for example', 'for two reasons', 'for three reasons', 'three main implications'). If the textual meta-discourse acts at an organisation level of the discourse, other strategies seem to be more clearly oriented to the relational profile between author and "model" scientific community. This objective seems to be pursued by means of:

a) The strategy of sincerity, through which the authors articulate reasons or provide clarifying inserts, sometimes 
contrasting even with themselves (e.g. "In contrast to one of our initial hypotheses");

b) The strategy of dialogism, through which the authors show that they hold "others" positioning in adequate esteem [11], by exploiting the capacity of dialogue between the various positions, whether they be "internal" or "external" ones (e.g. "Following concerns that the MINI may over diagnose some psychiatric disorders in custodial settings, we made the following adjustments")

c) The strategy of collaboration, aimed at determining the "collaborative" nature of their own approach, as well as the "constructive" function of knowledge of their own text. The idea of a "model reader" is incorporated in the text, also as a prediction of possible requests or observations, like in the examples "For further clarification about specific studies, we corresponded directly with the authors of the studies" and "Detailed results of this and other models described below are available from the authors on request".

Without considering the specific sections of the paper which, as everyone knows, quotations and further external references are indicated, like authorities or public services, with the function of reassuring the interlocutor, also with respect to the "ethical" dimension of the research, considering the particular nature of the themes addressed.

\section{The rhetoric of limitation}

All the sections of the papers also show the second macro-rhetoric, aimed at showing the limits of their own work, aware of the complexity of the disciplinary worlds, which forensic psychiatry borrows from and to which it tries to reply. These limits are constructed by means of various argumentative strategies that can operate "explicitly" and "implicitly". The first mode includes enunciative strategies that make the levels of uncertainty present in the text clear-cut. Sometimes long and argumentative lists of limits are found, expressed by lexical and syntactical expressions clearly related to uncertainty: For example "Nevertheless, there is still uncertainty about [...]. It is doubtful whether it should be [...] the ethical dilemma remains". Other times the complexity and problematization of the studies complete the framework of a mainly incomplete scenario, made up of partial considerations, failures, lack of detail, in which it is almost impossible for the reader to take a stance, orient themselves and seek certainties.

In order to assess the manner in which the social-epistemic rhetoric of the "limit" is organised, the pragma-linguistic indicators of mitigation are illuminating. By following the "functional" typology proposed by Caffi [8], the text authors reduce the force of their own statements by resorting to either "bushes" or "hedges". "Hedges" are made up of expressions that attenuate the illocutionary force of the statement. Specifically, they operate through moralizers of the epistemic commitment (perhaps, probably) as well as by subjectivizing (and thus restricting) epistemic certainties ("In our view, it is time to begin building an evidence base concerning the assessment, management and treatment of this subgroup"), as well as through a massive use of verbs and modals in the conditional. "Bushes", on the other hand, reduce the adhesion of the enunciator to the statement content, and this occurs by means of negation ("It is important not to be constrained by") or with mitigated choices of lexicon and approximations ("relative risk", "somewhat", "approximately").

Indeed the social-epistemic rhetoric of the "limit" is identifiable by further holistic strategies that operate at a textual level and assume a special importance precisely because they are focussed on validating the argumentation. The most relevant options are:

a) Hierarchy rearrangement, which consists of attributing importance to a reasoning with the aim of replacing or setting aside another (e.g. "It is therefore important to highlight that the pathways and mechanisms leading to violence in patients with schizophrenia should not be reduced to one set of risk factors");

b) Dilution, which consists of grading the level of precision or quantifying the results. It is as if Grice's maxim of quantity were openly violated, by using phrases of the kind "This usually involves [...] but is intended to [...] more were known [...]. It is generally assumed that... often";

c) Lateralisation, which consists of extending the range of possibility. This strategy has a similar function to the one carried out by digressions. In some cases, it may also act as exemplification, thus offering a case that, when inserted in other equivalent ones, makes it "one of many" (e.g.: "For example, a child psychiatrist may be unimpressed [...]. But a criminologist or epidemiologist might take...").

The social-epistemic rhetoric of the "limit", so obviously present in the texts, is also revealed through the continual swinging of the argumentation, which ends up assuming a "sinusoidal" trend at times. In particular, apart from the continuous alternation of assertiveness and uncertainty of their own work, this swinging even concerns the role of confirmation and disconfirmation carried out by the literature. It might, therefore, happen that the same factor is first assessed in terms of convenience and then in terms of problems, like when being "the first" to have performed a certain activity represents either a source of pride, or a necessary reference to the need for confirmation.

\section{Conclusion}

By presenting subjects concerning the connection between psychopathological epidemiology and criminal behaviour, the papers of our corpus respond to the needs of public utility and should provide useful thoughts on possible implications regarding prison detention, on programmes of intervention regarding situations of both potential danger and of support to the families. Against this difficult task, the enunciators of the papers seem to be intent on proceeding in an "assertive" and rigorous manner, attempting to produce effective contributions that can contribute to the theoretical and empirical debate on the presented questions. Overall, the strategies used will support the social-epistemic rhetoric of "reassurance" because the articles 
tend to provide cognitive guarantees to the reader, starting from connecting the accuracy of the proposed work to the solidity of the reported literature. However, the social dangerousness of the mentally ill person lacks the cognitive "closure" that would result from applying the results of the research to the services, in institutional contexts and in the pertinent laws. The complex problems at stake suggest the enunciators to voice the socialepistemic rhetoric of the "limit" enunciators to voice the socialepistemic rhetoric of the "limit".
Forensic psychiatry aggregates the challenges provided by two worlds that, against requests coming from real life, have to converge towards shared objectives, borrowing prospects of reciprocal enhancement from their respective theoreticalempirical scenarios. The "challenges" it must confront are ambitious: on the one hand to control what escapes the understanding, what we want to know, to examine, to predict; on the other to be responsible towards public life, the world of law and punishment, towards striving for stability, order and justice. 


\section{References}

1 Cantarini S, Abraham W, Leiss E (2014) Certainty-uncertainty-and the attitudinal space in between [SLCS 165]. Amsterdam: John Benjamin.

2 Shah SA (1978) Dangerousness and mental illness: some conceptual, prediction and policy dilemmas. In: Frederick C (ed.) Dangerous behaviour: a problem in law and mental health, Rockville, MD: NIMH, Washington, pp: 153-191.

3 Catanesi R, Carabellese F, Grattagliano I (2009) Treatment and control. How has the concept of psychiatric social danger changed? Italian J Psychopathol 15: 64-74.

4 Mininni G, Manuti A (2017) A rose is more than a rose. The diatextual constitution of subjects and objects. Text \& Talk 37: 243-263.

5 Berlin JA (1993) Post-structuralism, semiotics, and social-epistemic rhetoric: converging agendas. In: Enos T, Brown S (eds.) Defining the new rhetoric. Newbury Park, CA: Sage, pp: 137-176.
6 Cherwitz RA, Hikins JA (1986) Communication and knowledge: an investigation in rhetorical epistemology. Columbia: University of South Carolina Press.

7 Herrick JA (1997) The history and theory of rhetoric: an introduction. Scottsdale: Gorsuch Scarisbrick Publishers.

8 Caffi C (2007) Mitigation. Oxford: Elsevier.

9 Gross AG, Harmon JE, Reidy MS (2002) Communicating science. The Scientific Paper from the $17^{\text {th }}$ Century to the Present. Oxford University Press, NY, USA.

10 Hyland $K$ (2001) Bringing in the reader: addressee features in academic articles. Written Communication 18: 549-574.

11 Hermans HJM, Gieser T (2012) Handbook of dialogical self-theory. Cambridge University Press, Cambridge, UK. 